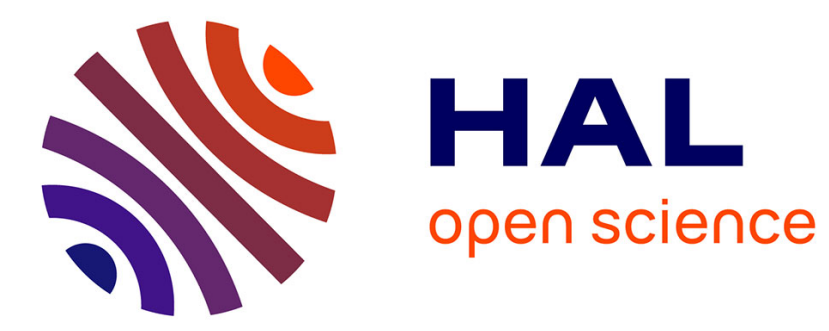

\title{
Informed horses are influential in group movements, but they may avoid leading
}

Julie Andrieu, Séverine Henry, Martine Hausberger, Bernard Thierry

\section{To cite this version:}

Julie Andrieu, Séverine Henry, Martine Hausberger, Bernard Thierry. Informed horses are influential in group movements, but they may avoid leading. Animal Cognition, 2016, 19 (3), pp.451-458. 10.1007/s10071-015-0945-2 . hal-01239818

HAL Id: hal-01239818 https://hal-univ-rennes1.archives-ouvertes.fr/hal-01239818

Submitted on 29 Feb 2016

HAL is a multi-disciplinary open access archive for the deposit and dissemination of scientific research documents, whether they are published or not. The documents may come from teaching and research institutions in France or abroad, or from public or private research centers.
L'archive ouverte pluridisciplinaire HAL, est destinée au dépôt et à la diffusion de documents scientifiques de niveau recherche, publiés ou non, émanant des établissements d'enseignement et de recherche français ou étrangers, des laboratoires publics ou privés. 


\title{
Informed horses are influential in group movements, but they may avoid leading
}

\author{
Julie Andrieu ${ }^{1,2,3,4}$. Séverine Henry ${ }^{3}$. Martine Hausberger ${ }^{3}$. \\ Bernard Thierry ${ }^{1,2}$
}

${ }^{1}$ Centre National de la Recherche Scientifique, Département Ecologie, Physiologie et Ethologie, Strasbourg, France

${ }^{2}$ Université de Strasbourg, Institut Pluridisciplinaire Hubert Curien, Strasbourg, France

${ }^{3}$ Centre National de la Recherche Scientifique, Université de Rennes 1, Ethologie Animale et Humaine, UMR 6552, Rennes, France ${ }^{4}$ Institute of Biology, University of Neuchâtel, Neuchâtel, Switzerland

Short title: Information and group movement in horses

\section{Corresponding author:}

Département Ecologie, Physiologie et Ethologie, IPHC, CNRS, 23 rue Becquerel, 67087 Strasbourg, France

Phone: (33) 388107458

Fax: (33) 388106906

Email: bernard.thierry@iphc.cnrs.fr 


\begin{abstract}
In species that move in cohesive groups, animals generally reach decisions through socially distributed processes, and individual knowledge is expected to influence collective decisionmaking. The pooling of information should not be considered a general rule, however, since conflicts of interest may occur between group members. When resources are limited or highly attractive, higher-ranking individuals can prevent others from accessing food, and subordinates may have an interest in withholding information its location. We investigated the role individual knowledge may play in recruitment processes in four groups of horses (Equus caballus). Animals were repeatedly released in a food search situation, in which one individual had been informed about the location of a preferred food, while another was a naïve control subject. Horses that were informed about the location of the feeding site were seen to approach the food source more steadily, and were followed by a higher number of group members than their uninformed counterparts. Recruitment processes appeared mostly passive. Amongst the informed subjects, lower-ranking individuals were overall less followed than the higher-ranking ones. Most lower-ranking horses arrived alone at the feeding site. Non-followed informed subjects spent less time in active walk and used direct paths less frequently than followed animals, they were joined by fewer partners at the attractive food source and spent more time feeding alone. This indicates that the influence of informed individuals on the behavior of other group members was a mixed process. Some horses brought nutritional benefits to their conspecifics by leading them to food supplies, whereas the behavior of others might be functionally deceptive.
\end{abstract}

Keywords Information . Deception . Recruitment . Collective movement . Social cognition . Equus caballus 


\section{Introduction}

In group-living species, the exploitation of resources is largely dependent on the sharing of information. Even when species live in habitats where food is dispersed, patches of more nutritive or appetent resources do occur. Cues or signals conveyed by individuals can inform their conspecifics about the location and quality of environmental resources, and especially about these preferred patches, from cues or signals conveyed by conspecifics (Galef and Giraldeau 2001). In some species, successful foragers can utter specific calls (Wilkinson 1992; Townsend and Manser 2012), and may also be recognized through signs such as olfactory cues (Galef and Stein 1985; Chauvin and Thierry 2005). Many animals are able to follow the gazes and pointing gestures of other individuals (e.g. Miklósi and Soproni 2006), and they can easily acquire information by monitoring the foraging behaviors of their conspecifics. In social herbivores such as goats (Capra hircus), for example, experiments show that individuals are able to locate higher quality feeding areas by observing conspecifics (Shrader et al. 2007).

In species that move in cohesive groups, animals reach consensus through socially distributed processes. Information pooling is thus expected to occur when group members choose their direction (Kummer 1968; Conradt and Roper 2005; Couzin et al. 2005; Petit and Bon 2010). However, the influence of individual knowledge on collective decision making remains poorly documented (Reebs 2000; Biro et al. 2006; Flack et al. 2012). It is known that the motivation levels of individuals play a significant role in recruitment processes (Petit and Bon, 2010). In plains zebras (Equus burchellii), the fact that lactating females head towards water holes more than other group members is explained by their higher drinking needs (Fischhoff et al. 2007). In sheep (Ovis aries), trained individuals moving toward an expected reward can elicit a collective movement (Pillot et al. 2010; Taylor et al 2011). Moreover, experiments in which pairs of pigs (Sus scrofa) had to find a food location showed that non-informed subjects followed an informed subject to the correct location (Held et al. 2000). Experimental studies in subgroups of non-human primates indicate that they are able to choose the path chosen by the best informed of their group mates (chimpanzee, Pan troglodytes: Menzel 1974; Tonkean macaque, Macaca tonkeana: Ducoing and Thierry 2004).

The pooling of information cannot be taken for granted in the context of group movements, as conflicts of interest may occur between individuals. When resources are limited, higherranking individuals can prevent others from accessing food, while subordinates can have an interest in withholding information about the location of resources. Both cases can impair foraging performances at the group level. For instance, subordinate chimpanzees only seize food when out of the sight of higher-ranking individuals (Menzel 1974; Hare et al. 2001). In monkey species, subordinates also perform detours or refrain from visiting the food site while they are 
being observed or followed by dominants (collared mangabey, Cercocebus torquatus: CoussiKorbel 1994; Tonkean macaque: Ducoing and Thierry 2003). Deceptive behaviors are not reported when there is a constant supply of food, which is the case for grazing animals. If the amount of resources decreases, however, competition levels rise and the use of informationwithholding tactics should become increasingly beneficial.

Here, we aimed to investigate the role played by individual knowledge in the recruitment process of groups of horses (Equus caballus). Equids form cohesive units in which individuals are linked by strong bonds and stable dominance relationships (Waring 2003; Feh 2005; Fureix et al. 2012). When moving from one place to another, their collective movements are typically based on consensus decisions, with different group members being followed, regardless of their dominance status (Bourjade et al. 2009, 2015; Wolter et al. 2014; Krueger et al. 2014). Horses have elaborate cognitive and communicative abilities (e.g., Lemasson et al. 2009; Proops and McComb 2010; Krueger and Flauger 2011; Gabor and Gerken 2014; Wathan and McComb 2014). For example, they can learn how to make a detour around an obstacle (Wolff and Hausberger 1996, Baragli et al. 2011; Osthaus et al. 2013), and they can intervene during affiliative interactions between their group mates (VanDierendonck et al. 2009; Schneider and Krueger 2012).

In the present study, groups of horses were repeatedly released in food search situation in which one of the individuals had been previously informed about the location of food. We predicted that if individual knowledge influenced collective movements, informed individuals should display recognizable behaviors that induce group members to adjust their own behavior and follow the informed animals more frequently than they follow naïve animals. Secondly, subordinate horses may use tactics to go to the feeding site alone and withhold information. Thus, we predicted that during movements during a baited site, lower-ranking individuals would be less frequently followed by their group mates than higher-ranking individuals.

\section{Methods}

Subjects

We studied four social groups of horses from January to April 2010. The number of adult individuals in each group was within the range of natural group size (see Waring 2003); three groups were composed of four individuals, and the fourth contained ten individuals. Table 1 provides information about the composition of groups. The individuals were not genetically related except the males Ton and Har (group 1), which were father and son, and the females Kan and Per (group 4), which were mother and daughter. All horses were accustomed to human presence, and the groups had been stable for 10 years for group 1, 5 years for group 2, and 2 
years for groups 3 and 4. Group 1 lived in a 5-ha outdoor enclosure including glades, shrubs and woods. Horses from group 2 had daily access to 2 -ha pastures and stayed in boxes at night. Groups 3 and 4 were kept outside in 2- and 1-ha meadows, respectively. In addition to grazing, horses were supplied with hay in groups 1, 3 and 4, and a mixture of soy and oats in group 2.

Table 1

\section{Testing procedure}

Testing consisted of releasing a group of horses in search of a feeding site. We defined ten potential feeding sites for each group, spread over an area of 1 hectare. Sites were located 30 to 100 meters from the spot chosen to release the horses. Because horses graze on widely dispersed food, information had to be related to very attractive food. Thus, tests were performed to determine preferred foods in each group, which led us to use carrots in groups 1, 3 and 4, and a mixture of soy and oats in group 2. Several $500 \mathrm{~g}$ piles of food were placed on the ground, $1.5 \mathrm{~m}$ apart, with the number of piles corresponding to the number of horses in a group. We ensured that the animals could not see the food from a distance of over $10 \mathrm{~m}$.

Two experimenters managed the study. In a first step, the horses were retained in an area where obstacles blocked any vision of feeding locations, then the experimenters baited one of the ten potential feeding sites. In a second step, the experimenters simultaneously led each of two horses by halter to a different site. One horse was allowed to briefly eat from a feeding site, and was informed this way about the location of food. The second horse was led to an unbaited site, and thus remained non-informed to serve as control individual. The first part of the route was identical for each subject tested in the same trial, with the experimenters leading the horses in two diametrically opposite directions for $50 \mathrm{~m}$. Each horse was then turned toward its respective site. An identical process was carried out when returning from the feeding site to the group. Note that the horses did not whinny at all during this stage of the experiment. We verified that no group mate approached and smelled the informed and uniformed subjects when the group was reunited. All the individuals were then released simultaneously and the trial started. The experimenters followed at a distance of about $30 \mathrm{~m}$ while continuously filming the animals, one focusing on the informed subject and its neighbors, and the other on the uninformed subject and its neighbors. The trials ended when the feeding site was entirely depleted. If none of the horses found the feeding site, the test ended 10 minutes after the 
subjects had been released. Following the completion of a trial, experimenters recorded the route followed by each of the subjects on a map.

In the group of 10 horses, we randomly tested each individual three times as an informed subject, and three times as uninformed. In groups composed of 4 horses, each horse was informed or uninformed three times in all possible pairings in randomized order. We performed a maximum of three trials per day in the groups of 4 individuals, and a maximum of 6 tests per day in the group of 10 . There was a pause of at least 40 minutes between trials. Three trials were discarded from the analysis, namely two that were disturbed by external noise, and one trial in which neither the informed subject nor any other horses departed when released. We performed a total of 63 trials.

Behavioral units

Experimenters recorded the following behaviors: Departure: An individual walks over a distance of at least five horse lengths from the departure point. Arrival: An individual enters a perimeter corresponding to two horse lengths around the feeding site. Departure latency: Time elapsed between group release and individual departure. Duration of travel: Time elapsed between the departure of the first individual (informed or control subject) and their arrival at the feeding site (note that if one of these individuals does not return to the feeding site, the duration of travel is stopped once the site has been depleted). Moving: An individual covers a minimal distance of three horse lengths without pausing. Gait: Quick gait (trot, gallop), active walk, or exploratory walk (walking with low neck carriage, head turned towards the ground). We recorded the duration of the different gaits. Neck position: The neck is held in either a low or a horizontal position, indicating whether the animal is in an exploratory or active walk towards a goal. Glance: A look toward other group members associated with a lateral move of the neck. Pause: An individual stops moving for at least 3 seconds. We recorded the duration of pauses and distinguished those associated with glances towards other group members from those occurring during other activities (ground sniffing, grazing, feeding, drinking, playing). Sudden direction change: A change of at least $30^{\circ}$ in the direction of movement over a maximal distance of one horse length. Direct path: An individual goes to the feeding site by the shortest route. Indirect path: an individual performing at least one direction change on its way to the feeding site. Following: An individual moves behind another horse in the same direction and with the same body orientation for at least $50 \%$ of the distance covered by the animal it is following; the number of followers is recorded after departure (first half of the travel distance) and before arrival (second half of the travel distance). Agonistic interaction: avoidance (an individual modifies its trajectory or moves away to avoid the approach of another horse) or 
flight caused by a threat or an attack (chase, kick, bite) by another individual. The videos of experiments were analyzed by the first author.

Assessment of dominance relationships and rank stability

For each study group, we collected all occurrences of agonistic behaviors in the field for 6 hours outside the context of information experiments. In stable groups living in naturalistic conditions, agonistic interactions are scarce (e.g. Fureix et al. 2012). We therefore carried out food competition tests to assess dominance relationships. In each group of 4 horses we performed one "1-pile test" and one "3-pile test" in which one or three 1-kg piles of food respectively were laid on the ground, $5 \mathrm{~m}$ apart, in front of each group. In the group of ten horses we conducted one "6-pile test" and one "9-pile test", i.e. competition tests with $N-1$ food piles for $N$ individuals as in other groups. Each test was recorded on video.

We used the agonistic interactions recorded during field observations, competition tests and experiments to evaluate dominance relationships and test rank stability over time. Each approach, threat or attack of an individual inducing avoidance, flight or retreat of another individual was considered as a "win" for the former and a "loss" for the latter. Dominance ranks were assessed from these observations using the Elo-rating method (Elo 1978; Albers 2001) in RStudio environment (V0.98.1102, RStudio, Inc.). The Elo-rating method simulates the establishment of dominance relationships by continually updating individual ranking scores: all individuals start with the same score (1000), which increases for the winner and decreases for the loser after each contest. The calculation of stability indices ranging from 0 (unstable) to 1 (stable) with the Elo-rating method (Neumann et al. 2011) yielded high indices in all groups of horses (groups 1, 2 and 3: 0.99, group 4: 0.98). This indicates that ranks were stable across situations, i.e. during field observations, food competition tests and experiments. Individuals ranking in the upper half of the hierarchy of their group were classified as high ranking (score above 1000), those belonging to the lower half as low ranking (score below 1000).

As usually observed in competition tests, social rank affected individual feeding time: lowerranking individuals indeed fed for shorter durations (15.9 $\pm 16.0 \%$ of test duration) than higherranking individuals $(75.4 \pm 32.9 \%)$ during competition tests (Mann-Whitney test, $N_{1}=11, N_{2}=$ $11, W=110, P<0.001)$.

\section{Analysis}

We compared the behavior of informed and control subjects using the Wilcoxon signed-rank test, exact procedure, computed in RStudio environment (V0.98.1102, RStudio, Inc.). We compared the behavior of subjects traveling alone or in a group using the Mann-Whitney test, 
exact procedure, with the same software. We considered an informed subject to be traveling alone when no group member was seen following the subject on the second half of the journey, or when the informed subject arrived at the feeding site alone and could feed on the resource for at least 45 seconds without being joined by another individual. We controlled for multiple testing following the procedure of Benjamini and Hochberg (1995). We used the Fisher's exact test to evaluate the influence of dominance ranks by comparing the behaviors of horses traveling alone or in a group. All tests were two-tailed. The significance level was set at 0.05.

\section{Results}

In $69 \%$ of cases, the informed subject returned to the feeding site, in $19 \%$ an uninformed individual discovered the food site by itself, and in $19.5 \%$ none of the horses reached the site. Only two of the informed subjects systematically failed to discover the feeding site. A total of 379 agonistic interactions were observed at the feeding site, representing $7.43 \pm 7.45$ agonistic interactions per trial. Nevertheless, $90.3 \pm 18.5 \%$ of the animals that had arrived at the feeding site (mean $\pm \mathrm{SD}$ ) were able to consume food (i.e. $2.49 \pm 1.32$ individuals), indicating that most of the horses arriving at the feeding site had access to food.

Comparison of the behaviors of informed and control subjects

When averaging the results of successful trials involving the same informed subject (i.e.trials in which the individual returned to the food site) we found that the behavior of informed horses clearly differed from that of control individuals. Compared to control individuals, informed horses spent more time moving, showing a higher proportion of active walk with a horizontal neck position. Although they attributed less time to pauses associated with activities, this was not true for pauses involving monitoring (Table 2). The comparison of the number of glances at departure (i.e. the first part of the journey over a distance of five horse lengths) between informed and control subjects yielded a probability level of 0.05 (Table 2). The percentage of time spent moving was significantly higher in informed subjects than in control individuals, and this was associated with a higher percentage of time with a horizontal neck position in informed subjects (Table 2). No statistically significant differences appeared between informed and control subjects for departure latency and the percentage of time spent traveling with quick gaits (trot and gallop), which remained rare (Table 2). Lastly, the informed subjects were followed by a higher number of individuals than the control subjects.

Table 2 
Dominance rank and behaviors of followed and non-followed informed subjects

Twelve of the 20 informed subjects having discovered the feeding site could travel alone. Lower-ranking individuals traveled alone more frequently than higher-ranking individuals (lower-ranking subjects: 7 subjects traveling alone at least once versus 1 always traveling in a group; higher-ranking subjects: 3 versus 9; Fisher's exact test, $P=0.020)$. When informed, lower-ranking animals were thus followed less frequently than higher-ranking animals. To understand whether this could be explained by their behavior, whatever their dominance status, we compared the behaviors of horses that were always followed by other group members with those of individuals that traveled alone. It appeared that the non-followed subjects spent less time in active walk and used fewer direct paths than the followed subjects. They also tended to exhibit more frequent sudden direction changes, but this effect did not reach statistical significance (Table 3). Non-followed subjects spent more time feeding alone at the food site, and after their arrival they were joined by fewer partners than followed subjects (Table 3 ). No significant differences were observed regarding the number of glances per minute and the percentage of time moving with a horizontal neck position (Table 3).

Table 3

\section{Discussion}

Informing horses about the location of an attractive food site significantly influenced their behavior, both at the individual and collective levels. Individuals knowing the location of the feeding site were followed by a larger number of group members than their uninformed counterparts, demonstrating that individuals that possessed relevant information about their environment were more influential than others in recruiting conspecifics.

We expected informed horses to display behaviors prompting others to follow them. In nonhuman primates, departing individuals usually perform back glances towards other group members, which increases the number of individuals recruited in collective movements (Sueur and Petit 2008; Meunier et al. 2008). Here, we did not find significant differences between informed and control subjects in departure latency, but glances appeared more frequent in informed subjects than in their uninformed counterparts.

Informed and uninformed individuals did not show any differences in vigilance behavior or quick gaits during travel. By contrast, the informed subjects spent a higher proportion of time moving, with a horizontal neck position associated with steady walking and a lower proportion 
of time pausing, meaning that these individuals moved more steadily toward the food source. The absence of the coercive behaviors sometimes observed among horses in other contexts (Feist and McCullough 1976; Bourjade et al. 2009; Krueger et al. 2014) points out to mostly passive recruitment processes. This is in line with previous results showing that departing individuals usually do not use vocalizations or body postures to initiate collective movements (Bourjade et al. 2009; Krueger et al. 2014). It is known that horses are able to use the orientation of the face and ears of other individuals as indicators of attention (Wathan and McComb 2014). The behaviors of informed individuals likely reflected their motivation to go to the feeding site. The other group mates may therefore have used their moves as cues, as reported during previous experiments in other ungulates (Held et al. 2000; Pillot et al. 2010) and in non-human primates (Menzel 1974; Ducoing and Thierry 2004).

In the context of food competition, lower-ranking individuals had shorter feeding times than higher-ranking individuals. If horses were able to withhold information, subordinate individuals should travel alone and perform behaviors that aimed to avoid leading others to the feeding site. Our study confirmed this with evidence that most of the horses traveling alone were low ranking, whereas a majority of those followed by other group mates were high ranking. Besides, it appeared that followed and non-followed horses differed in their behaviors regardless of their dominance status. Individuals traveling alone used indirect paths more frequently to return to the feeding site, and spent less time actively walking than animals accompanied by others. These individuals actually attracted a small number of group mates on site, and they spent more time feeding alone. It is worth noting that traveling alone in the larger group might have allowed some higher-ranking individuals to avoid competition with other higher-ranking partners.

The slow gait and indirect paths exhibited by horses mirrored the deceiving tactics used by subordinates in chimpanzees and monkeys to conceal information about baited locations (Menzel 1974; Coussi-Korbel 1994; Ducoing and Thierry 2003). It is worth mentioning that several of the behavioral sequences observed in horses were close to those described in nonhuman primates: waiting for group mates to leave first before moving towards the feeding site; slowly moving away from the group then going to the baited site alone; performing pauses, then going to the feeding site while mates are involved in other activities. It should be stressed that such observations do not imply that individuals intentionally misled their conspecifics. Horses may have associatively learned to anticipate the consequences of their own behavior. Future studies should look more closely at whether horses can indeed inhibit actions liable to attract the attention of potential competitors, which would be the prerequisite to assuming these behaviors to be functionally deceptive (Whiten and Byrne 1988; Ducoing and Thierry 2003). An alternative explanation would be that group mates would more readily follow higher-ranking 
individuals than lower-ranking ones. However, the study of group movements consistently shows that dominance relationships have no significant influence on recruitment processes or "leadership" in horses (Waring 2003; Feh 2005; Krueger et al. 2014; Wolter et al. 2014; Bourjade et al. 2015; Briard et al. 2015).

Our results show that the influence of informed individuals on the behavior of other group members could be a mixed process (Menzel 1974; Ducoing and Thierry 2004). Informed horses were followed by a higher number of group members than uninformed individuals, thus providing their conspecifics with nutritional benefits. Although not necessarily intentional, such behaviors were nevertheless cooperative. Moreover, the behaviors of horses traveling alone might be functionally deceptive, allowing them to avoid social competition and exploit resources in a selfish way. It should be added that a number of factors other than individual knowledge may affect collective decision making (Couzin and Krause 2003; Petit and Bon 2010). Additional work will be necessary on further populations, both in captivity and in the wild, to verify the accuracy and generality of our conclusions.

Acknowledgments We would like to thank Louis Menier and l'Élevage Kergane (Saint-Brieucde-Mauron), as well as Martine Clerc and Mireille Dumond at the Écurie Terre d'Illich (Mériadec, Plumergat) for their logistical and practical support. We are grateful to Hélène Thieltges for her valuable assistance in experiments. The study benefited from financial support from the Groupement de Recherche d'Ethologie (GDR 2822). The experiments complied with the current French laws governing animal research.

\section{References}

Albers P (2001) Elo-rating as a tool in the sequential estimation of dominance strengths. Anim Behav 61:489-495

Baragli P, Vitale V, Paoletti E, Sighieri C, Reddon AR (2011) Detour behaviour in horses (Equus caballus). J Ethol 29:227-234

Biro D, Sumpter DJT, Meade J, Guilford T (2006) From compromise to leadership in pigeon homing. Curr Biol 16:2123-2128

Benjamini Y, Hochberg Y (1995) Controlling the false discovery rate: a practical and powerful approach to multiple testing. J Roy Stat Soc B 57:289-300

Bourjade M, Thierry B, Maumy M, Petit O (2009) Decision-making in Przewalski horses (Equus ferus przewalskii) is driven by the ecological contexts of collective movements. Ethology 115:321-330 
Bourjade M, Thierry B, Hausberger M, Petit O (2015) Is leadership a reliable concept in animals? An empirical study in the horse. Plos One 10:e0126344

Briard L, Dorn C, Petit O (2005) Personality and affinities play a key role in the organisation ofcollective movements in a group of domestic horses. Ethology 121:888-902.

Chauvin C, Thierry B (2005) Tonkean macaques orient their food search from olfactory cues conveyed by group mates. Ethology 111:1-10

Conradt L, Roper TJ (2005) Consensus decision-making in animals. Trends Ecol Evol 20:449456

Coussi-Korbel S (1994) Learning to outwit a competitor in mangabeys (Cercocebus torquatus torquatus). J Comp Psychol 108:164-171

Couzin ID, Krause J (2003) Self-organization and collective behavior in vertebrates. Adv Stud Behav 32:1-75

Couzin ID, Krause J, Franks NR, Levin SA (2005) Effective leadership and decision-making in animal groups on the move. Nature 433:513-516

Ducoing A M, Thierry B (2003) Withholding information in semifree-ranging Tonkean macaques (Macaca tonkeana). J Comp Psychol 117:67-75

Ducoing AM, Thierry B (2004) Following and joining the informed individual in semifreeranging Tonkean macaques (Macaca tonkeana). J Comp Psychol 118:413-420

Elo AE (1978) The rating of chess players, past and present. Arco Pub, New York, NY.

Feh C (2005) Relationships and communication in socially natural horse herds. In The domestic horse: the origins, development and management of its behavior (DS Mills, SM McDonnell, eds), Cambridge University Press, Cambridge, pp 83-91.

Feist JD, McCullough DR (1976) Behavior patterns and communication in feral horses. Z Tierpsychol 41:337-341

Fischoff IR, Sundaresan SR, Cordingley J, Larkin HM, Sellier MJ, Rubenstein DI (2007) Social relationship and reproductive state influence leadership roles in movements of plain zebra Equus burchellii. Anim Behav 73:825-831

Flack A, Pettit B, Freeman R, Guilford T, Biro D (2012) What are leaders made of? The role of individual experience in determining leader-follower relations in homing pigeons. Anim Behav 83:703-709

Fureix C., Bourjade M, Henry C, Sankey C, Hausberger M (2012) Exploring aggression regulation in managed groups of horses Equus caballus. Appl Anim Behav Sci 138:216-228.

Gabor G, Gerken M (2014) Shetland ponies (Equus caballus) show quantity discrimination in a matching-to-sample design. Anim Cogn 17:1233-1243 
Galef BG, Giraldeau LA (2001) Social influences on foraging in vertebrates: causal mechanisms and adaptive functions. Anim Behav 61:3-15

Galef BG, Stein M (1985) Demonstrator influence on observer diet preference: analyses of critical social interactions and olfactory signals. Anim Learn Behav 13:31-38

Hare B, Call J, Tomasello M (2001) Do chimpanzees know what conspecifics know? Anim Behav 61:139-151

Held S, Mendl M, Devereux C, Byrne RW (2000) Social tactics of pigs in a competitive foraging task: the 'informed forager' paradigm. Anim Behav 59:569-576

Krueger K, Flauger K, Farmer K, Hemelrijk CK (2014) Movement initiation in groups of feral horses. Behav Proc 103:91-101

Krueger K, Flauger B (2011) Olfactory recognition of individual competitors by means of faeces in horse (Equus caballus). Anim Cogn 14:245-257

Kummer H (1968) Social organization of hamadryas baboons. Karger, Basel

Lemasson A, Boutin A, Boivin S, Blois-Heulin C, Hausberger M (2009) Horse (Equus caballus) whinnies: a source of social information. Anim Cogn 12:693-704

Menzel EW (1974) A group of young chimpanzees in a one-acre field. In Behavior of nonhuman primates, Vol 5 (AM Schrier, F Stollnitz, eds), Academic Press, New York, NY, pp $83-153$

Meunier H, Deneubourg JL, Petit JL (2008) How many for dinner? Recruitment and monitoring by glances in capuchins. Primates 49:26-31

Miklósi A, Soproni K (2006) A comparative analysis of animals' understanding of the human pointing gesture. Anim Cogn 9:81-93

Neumann C, Duboscq J, Dubuc C, Ginting A, Irwan AM, Agil M, Widdig A, Engelhardt A (2011) Assessing dominance hierarchies: validation and advantages of progressive evaluation with Elo-rating. Anim Behav 82: 911-921

Osthaus B, Proops L, Hocking I, Burden F (2013) Spatial cognition and perseveration by horses, donkeys and mules in a simple A-not-B detour task. Anim Cogn 16:301-305

Petit O, Bon R (2010) Decision-making processes: the case of collective movements. Behav Proc 84:635-647

Pillot MH, Gautrais J, Gouello J, Michelena P, Sibbald A, Bon R (2010) Moving together: incidental leaders and naïve followers. Behav Proc 83:235-241.

Proops L, McComb K (2010) Attributing attention: the use of human-given cues by domestic horses (Equus caballus). Anim Cogn 13:197-205

Reebs SG (2000) Can a minority of informed leaders determine the foraging movements of a fish shoal? Anim Behav 59:403-409 
Schneider G, Krueger K (2012) Third-party interventions keep social partners from exchanging affiliative interactions with others. Anim Behav 83:377-387

Sueur C, Petit O (2008) Shared or unshared consensus decision in macaques? Behav Proc 78:84-92

Shrader AM, Kerley GIH, Kotler BP, Brown JS (2007) Social information, social feeding, and competition in group-living goats (Capra hircus). Behav Ecol 18:103-107

Taylor DB, Price IR, Brown WY, Hinch GN (2011) Effects of Merino flock size, paddocks complexity and time of day on response to trained leaders. Small Rum Res 97: 35-40

Townsend SW, Manser MB (2012) Functionally referential communication in mammals: the past, present and the future. Ethology 118:1-11

VanDierendonck MC, de Vries H, Schilder MBH, Colenbrander B, Porhallsdóttir AG

Sigurjónsdóttir H (2009) Interventions in social behaviour in a herd of mares and geldings. Appl

Anim Behav Sci 116:67e 73

Waring GH (2003) Horse behavior. Noyes Publishing, Norwich, NY

Wathan, J, McComb (2014) The eyes and ears are visual indicators of attention in domestic horses. Curr Biol 24:R677-R679

Whiten A, Byrne RW (1988) Tactical deception in primates. Behav Brain Sci 11:233-273

Wilkinson GS (1992) Information transfer at evening bat colonies. Anim Behav 44:501-518

Wolff A, Hausberger M (1996) Learning and memorisation of two different tasks in horses: the effects of age, sex and sire. Appl Anim Behav Sci 46:137-143

Wolter N, Pantel N, Stefanski V, Möstl E, Krueger K (2014) The role of an alpha animal in changing environmental conditions. Physiol Behav 133:236-243 
Table 1 Composition of groups

\begin{tabular}{lllll}
\hline Individual & $\begin{array}{l}\text { Age } \\
\text { (years) }\end{array}$ & Sex & $\begin{array}{l}\text { Dominance Breed } \\
\text { rank }\end{array}$ \\
\hline Group 1 & & & & \\
Ton & 24 & stallion & High & Haflinger \\
Ald & 21 & gelding & Low & Pony (unknown origin) \\
Har & 14 & gelding & Low & Haflinger x Connemara pony \\
Huk & 14 & stallion & High & Appaloosa
\end{tabular}

Group 2

$\begin{array}{lllll}\text { Dol } & 19 & \text { mare } & \text { Low } & \text { Selle français } \\ \text { Gua } & 16 & \text { mare } & \text { High } & \text { Selle français } \\ \text { Han } & 15 & \text { mare } & \text { High } & \text { Selle français } \\ \text { Nis } & 9 & \text { mare } & \text { Low } & \text { Selle français }\end{array}$

Group 3

$\begin{array}{lllll}\text { Bon } & 17 & \text { mare } & \text { Low } & \text { Highland pony } \\ \text { Qui } & 17 & \text { gelding } & \text { Low } & \text { Lusitano } \\ \text { Jad } & 13 & \text { mare } & \text { High } & \text { French Saddle Pony } \\ \text { Ros } & 5 & \text { gelding } & \text { High } & \text { French Saddle Pony }\end{array}$

Group 4

\begin{tabular}{lllll} 
Ild & 17 & mare & Low & Pony (unknown origin) \\
Kan & 12 & mare & High & Pony (unknown origin) \\
Orp & 8 & mare & Low & Pony (unknown origin) \\
Teq & 8 & mare & Low & Pony (unknown origin) \\
Per & 7 & mare & High & Pony (unknown origin) \\
Pip & 7 & gelding & Low & Pony (unknown origin) \\
Que & 6 & mare & High & Pony (unknown origin) \\
Mac & 5 & gelding & High & Pony (unknown origin) \\
Rhu & 5 & gelding & High & Pony (unknown origin) \\
Sal & 5 & mare & Low & Pony (unknown origin) \\
\hline
\end{tabular}


Table 2 Comparison of informed and control subjects (Wilcoxon test, $\mathrm{N}=22$ )

\begin{tabular}{lccccc}
\hline Variable & $\begin{array}{c}\text { Informed subject } \\
\text { mean } \pm \mathrm{SD}\end{array}$ & $\begin{array}{c}\text { Control subject } \\
\text { mean } \pm \mathrm{SD}\end{array}$ & $V$ & $\begin{array}{c}P \text {-value } \\
\text { Corrected } P \text {-value } \\
\text { (Benjamini-Hochberg) }\end{array}$ \\
\hline Moving (\% duration) & $74.2 \pm 29.9$ & $31.3 \pm 22.0$ & 248 & $<0.001$ & $<0.001$ \\
Horizontal neck position (\% duration) & $50.8 \pm 33.0$ & $25.7 \pm 16.9$ & 209 & 0.006 & $<0.012$ \\
Pause when monitoring (\% duration) & $5.04 \pm 6.56$ & $2.38 \pm 4.03$ & 116 & 0.064 & 0.091 \\
Pause in other activities (\% duration) & $18.2 \pm 29.9$ & $64.7 \pm 24.8$ & 5 & $<0.001$ & $<0.001$ \\
Quick gait (\% duration) & $5.18 \pm 12.90$ & $0.94 \pm 4.11$ & 42 & 0.160 & 0.183 \\
Departure latency (seconds) & $32.9 \pm 44.8$ & $39.1 \pm 63.1$ & 99 & 0.585 & 0.585 \\
Glances following departure (frequency) & $0.27 \pm 0.53$ & 0 & 21 & 0.031 & 0.050 \\
Number of followers & $0.80 \pm 1.05$ & $0.09 \pm 0.29$ & 73 & 0.004 & 0.012 \\
\hline
\end{tabular}


Table 3 Comparison of the behaviors of informed horses moving singly or in a group (Mann-Whitney test)

\begin{tabular}{|c|c|c|c|c|c|}
\hline Variable & $\begin{array}{c}\text { Moving in a group } \\
\text { mean } \pm \mathrm{SD} \\
(N=8)\end{array}$ & $\begin{array}{c}\text { Moving singly } \\
\text { mean } \pm \mathrm{SD} \\
(N=12)\end{array}$ & $W$ & $P$-value & $\begin{array}{c}\text { Corrected } P \text {-value } \\
\text { (Benjamini-Hochberg) }\end{array}$ \\
\hline Active walk ( $\%$ duration) & $73.0 \pm 23.4$ & $47.7 \pm 22.9$ & 19 & 0.025 & 0.044 \\
\hline Direct path (proportion over total number) & $0.69 \pm 0.38$ & $0.24 \pm 0.39$ & 20 & 0.020 & 0.047 \\
\hline Sudden direction change (number per minute) & $0.11 \pm 0.20$ & $0.81 \pm 0.92$ & 72 & 0.052 & 0.072 \\
\hline Feeding alone on site (seconds) & $31.8 \pm 35.4$ & $311 \pm 323$ & 84.5 & 0.003 & 0.022 \\
\hline Maximum number of subjects on site & $3.30 \pm 0.95$ & $2.05 \pm 0.94$ & 20 & 0.008 & 0.028 \\
\hline Glance (number per minute) & $0.21 \pm 0.38$ & $0.14 \pm 0.31$ & 41.5 & 0.531 & 0.531 \\
\hline Horizontal neck position ( $\%$ duration) & $55.2 \pm 39.0$ & $42.8 \pm 23.6$ & 38 & 0.473 & 0.551 \\
\hline
\end{tabular}

